\title{
Business Recovery Continues
}

\author{
by ROGER W. SPENCER
}

HE ECONOMY recently passed the two-year mark in its recovery from the recession which ended in November $1970 .^{1}$ The record of business cycles over the past two decades indicates that two of the three previous recoveries were halted in less than three years. The recovery following the recession of 1953-54 lasted two years and eleven months, and the recovery following the 1957-58 downturn endured two years and one month.

However, the expansion following the 1960-61 recession moved past the so-called "fragile" stage into a mature, well-rounded recovery which, despite brief periods of slowing, did not end until late 1969. Stabilization actions played a strong role in determining the duration of the expansion in all cases.

The evidence surveyed by this article indicates that the current recovery is no longer in the fragile stage of its development. Recent stimulative monetary and fiscal actions combined with the present upward momentum of the economy suggest that the current business expansion might well continue for an extended period of time.

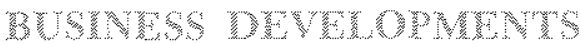

One way of gauging the current strength of the econorny is by relating its progress to earlier recoveries at comparable stages in the business cycle. Several economic variables are compared in Chart I by setting their actual values equal to 100 at the trough of the various cycles. An analysis of the recovery by spending sectors follows.

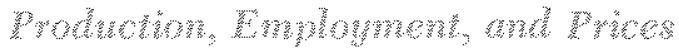

The data for four economic indicators in the chart are compiled to give a comparison of the current recovery with the average of the three preceding ones.

\footnotetext{
Turning points cited in this article are those identifed by the National Bureau of Lcononic Research.
}

The charts trace out the movements of real product, industrial production, payroll employment, and the GNP price deflator from eight quarters prior to the recession troughs to eight quarters after.

The top tier of the chart shows GNP in 1958 prices, the broadest measure of overall real economic activity. Real product did not increase as rapidly in the first year of the latest recovery period as in previous comparable periods. However, real product accelerated to the point where it matched the average of the previous periods after seven quarters and surpassed the average by the eighth quarter. A similar picture is illustrated by industrial production. Industrial production growth was sluggish in 1971 in comparison with the first year of previous recoveries. By the end of the second year of the recovery, the gap between the two lines had narrowed sharply.

Payroll employment did not decline as much in 1970 as the average of the previous recessions, nor did the unemployment rate rise to the levels observed in the $1957-58$ and $1960-61$ recessions. Partially reflecting the mildness of the downturn, employment gains in 1971 were modest in comparison with the first year of other recoveries. However, payroll employment rose at a more rapid rate in the second year of the latest recovery than the average rate of the previous corresponding periods.

Prices, as measured by the GNP price deflator, increased at a much more rapid rate prior to the trough of the latest recession than in previous recessions. Not surprisingly then, price advances were more difficult to curb in 1971 than in the first year of previous recoveries. It can be seen by the slopes of the two lines that after the first year the progress in slowing inflation was quite comparable with the average of the previous periods.

In summary, the indicators of real economic activity suggest that 1971 was weaker than the average 


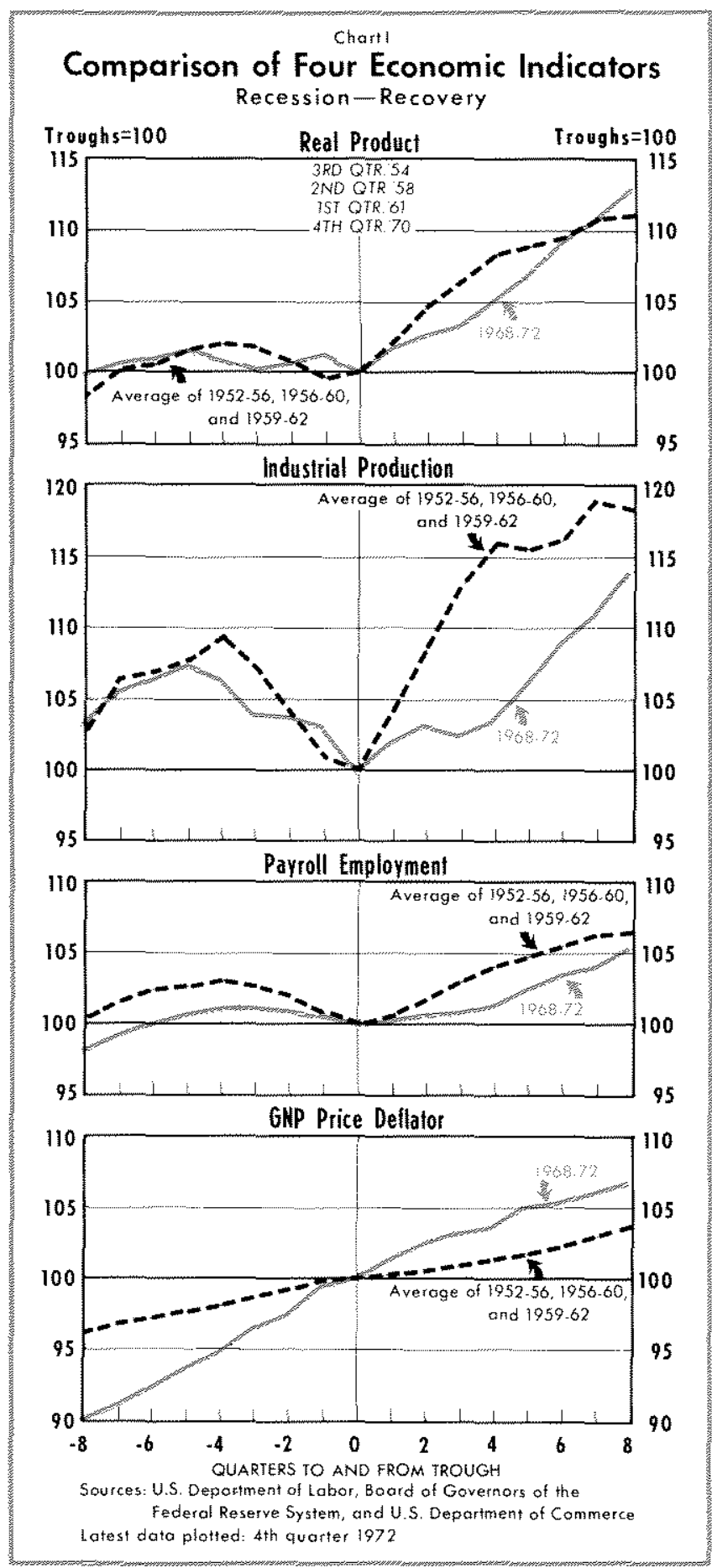

initial recovery year and 1972 was considerably stronger than the average second year of a recovery period. Moreover, there is no apparent slowing indicated by fourth quarter 1972 data. Real product, for example, increased at an 8.4 percent annual rate from the third to the fourth quarter of 1972 , compared with a 7.2 percent rise in the preceding year. The current strength of the indicators of real growth, given some

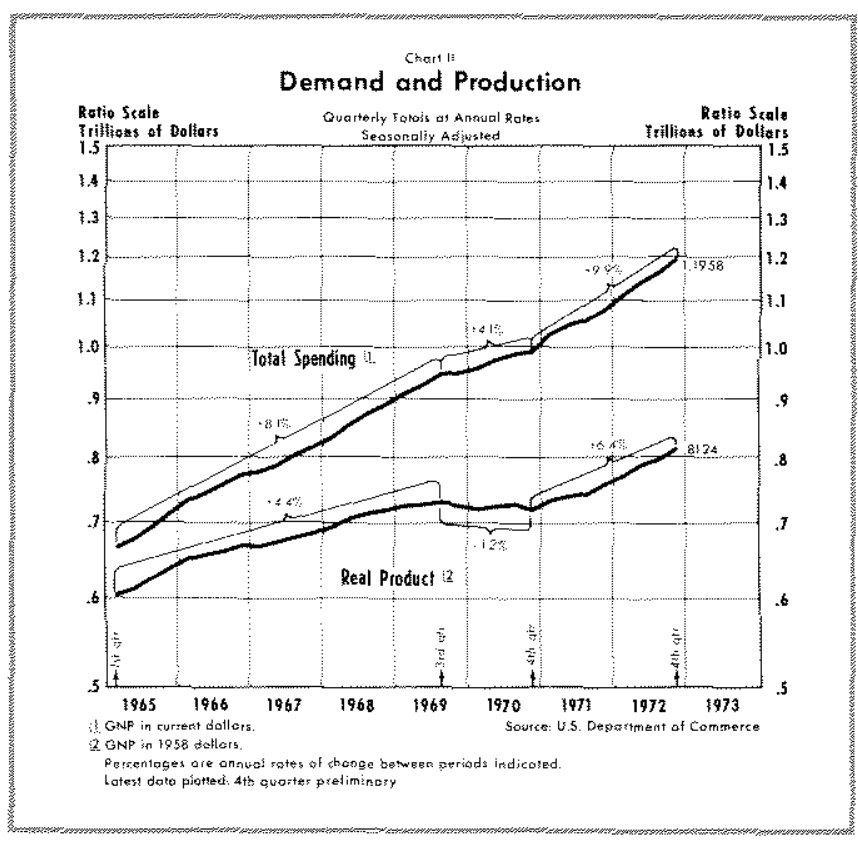

remaining capacity for expansion, imply considerable economic momentum.

\section{Sponing solors}

An analysis of the various spending components indicates sectors that have been increasing at slow or rapid rates in the past and suggests which direction they may take in the near future. Several components of GNP are traced in Chart III, which is similar in terms of cyclical comparisons to Chart I. All GNP components in Chart III are price deflated in order to separate the real trends from the price developments.

Consmanym - Consumer outlays, in real terms, have increased somewhat more rapidly over the first two years of the most recent recovery than the average of comparable periods in previous recoveries. At the end of the first year of the latest recovery, consumption expenditures were slightly below the average for the previous periods. However, during the second year of the expansion, consumer expenditures rose considerably above the "average" Ine. This recent spurt in consumption spending occurred despite substantial tax overwithholding in 1972

Purchases of durable goods, especially autos, have accounted for a sizable portion of the recent gains in consumer expenditures. The elimination of the excise tax on automobiles and a re-alignment of international exchange rates have been important stimuli to domestic automolile sales.

mind hecsman - Nonresidential investment expenditures, which consist of producers' durable goods 


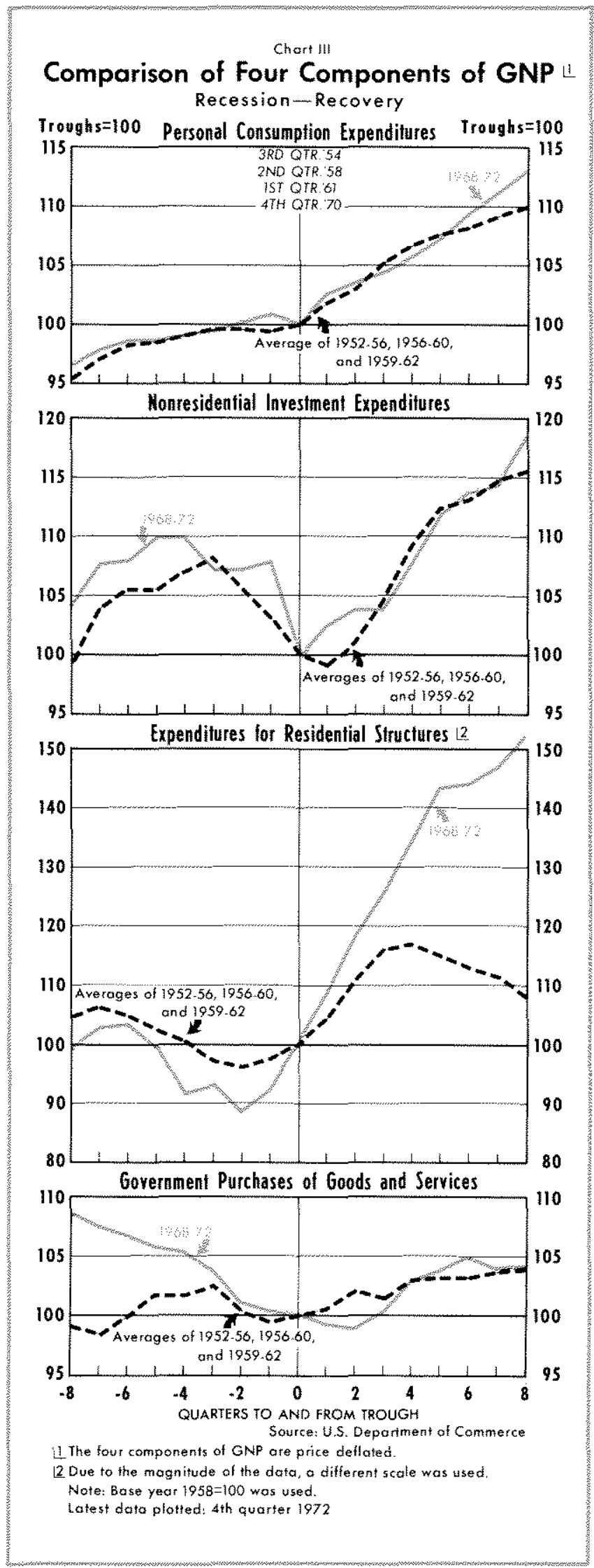

and structures, moved approximately in line with the index of previous periods until the eighth quarter following the trough. At this point, expenditures (price deflated) in the recent recovery moved well above the line representing the average of the three preceding periods. Business assistance progranus, such as the investment tax credit and accelerated depreciation, have been partially responsible for recent gains in plant and equipment expenditures. Surveys, such as those of the Department of Commerce, indicate that plant and equipment expenditures in 1973 may well surpass those of the year just ended.

Outlays for residential structures demonstrate the most significant departure from previous recovery periods. The expenditure patterns for residential structures in the current and earlier cycles are fairly similar during the eight quarters preceding the trough of the recession. However, these expenditures (in real terms) accelerated at a very rapid rate in the first four quarters after the trough of the 1969-70 recession and did not turn down as they did in the second year of previous recovery periods.

A fall in mortgage rates from 8.4 percent at the end of 1970 to 7.6 percent at the end of 1972 provided stimulus to the housing sector as did the 17 percent annual rate of increase in deposits at savings institutions over that period. ${ }^{2}$ Although government-subsidized housing starts fell from over 425,000 units in 1971 to 337,000 units in 1972 , all private starts rose from 2.1 million to about 2.4 million. A continued slowing of subsidized housing starts, therefore, would not necessarily signal the end of the housing boom if conditions remained favorable to the private housing sector. However, mortgage interest rates and interest rates competitive with those of savings institutions have recently begun to rise. These two factors may tend to slow the recent rapid growth in housing starts.

Covernas - Government purchases of goods and services, which include state, local, and Federal Government purchases, declined considerably in the eight quarters preceding the trough of the latest business cycle and did not rise until the latter part of the first year of recovery. In 1972, however, the index of these price-deflated outlays topped their previous average for all four quarters. State, local and Federal nondefense expenditures have risen rapidly in recent years, but have not been subject to much year-to-year varia-

\footnotetext{
"Mortgage interest rate data are based on the effective rate on new homes. The mortgage rate for 1970 is the average rate for the last three months of the year, and the rate for 1972 is the average of October and November.
} 
tion. Thus, fluctuations in the 1968-72 line on the chart largely reflect movements in defense expenditures.

oner sectors - With regard to other spending sectors, net exports have not yet shown much response to the devaluation of the dollar, but a significant turnaround within the next year or two is likely. Business inventories have not increased as rapidly as in previous recovery periods. The low inventory/sales ratio of 1.47 at the end of 1972 compares to 1.68 in the fourth quarter of 1970 and an average of $1.52 \mathrm{in}$ the ten-year period ending in 1969. This suggests possible rapid inventory accumulation in the near future.

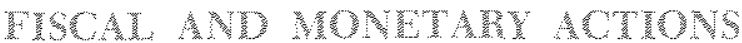

In addition to the current upward momentum of the economy, recent stabilization actions also suggest the likelihood of continued growth. The 1971-72 recovery has been fueled by basically stimulative fiscal and monetary actions.

\section{Wach Dowoloments}

Federal expenditures increased at a rapid pace in 1972. On a national income accounts basis, these expenditures rose 15.6 percent from the fourth quarter of 1971 to the fourth quarter of 1972 , compared with a 9 percent increase in the year ending late 1971 and a 5.8 percent annual rate of increase in the preceding two years. The pattern of accelerating Federal expenditures has had a pronounced effect on the net budget position over the past few years.

The Federal budget, after being in surplus by $\$ 4.7$ billion in fiscal year 1969, was in deficit by increasing amounts the next three years. The deficit was $\$ 1.3$ billion in $1970, \$ 19.7$ billion in 1971 , and $\$ 21.1$ billion in 1972. Presently, the anticipated deficit for fiscal year 1973 is $\$ 26.6$ billion. ${ }^{3}$

Budget deficits stimulate the economy in two ways. First, there is usually a temporary direct influence of the budget on economic activity regardless of how the deficit is financed. Second, sizable deficits tend to be underwritten by monetary expansion.

In the first half of calendar year 1973, the Treasury is expected to borrow funds from the market, largely in order to meet refunds of last year's tax overwithholding. Generally, the first half of the calendar year is marked by little or no Treasury borrowing because

The recently released budget message for fiscal year 1974 , which has not yet been acted unon by Congress, projects a $\$ 12.5$ billion defict on a national income acoounts basis. of heavy inflows of tax receipts. Since the private sector is also expected to compete vigorously for funds in the near future, upward pressure on some interest rates is likely. Efforts by stabilization authorities to resist the rise in interest rates could result in accelerated monetary growth.

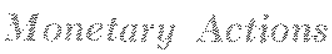

Monetary actions of the Federal Reserve and Treasury are reflected in movements of monetary aggregates and interest rates. Although the relationship between the aggregates and interest rates is complex, one pattern which has emerged over the years is a tendency for both to rise during much of the upswing phase of the business cycle. Initially, an acceleration in the rate of increase of monetary aggregates is reffected in a decline in interest rates as the monetary authorities attempt to stimulate spending. As economic activity begins to accelerate in response to the increased monetary expansion, the demand for credit increases, resulting in higher interest rates. Sometime later, as the economy nears full capacity utilization, the rate of inflation gradually accelerates. The acceleration of price advances leads creditors to demand yet higher interest rates to offset anticipated future inflation.

Moneravy Agregates - Purchases and sales of U.S. Treasury securities by the Federal Reserve are reflected in changes in the monetary base, a combined balance sheet of the Federal Reserve and Treasury "monetary" accounts. It has been observed that over a period of several months, the growth pattern of the money stock corresponds to that of the monetary base. In turn, marked and sustained changes in the money stock have led changes in economic activity by a few months.

One approximate method of gauging monetary policy actions in the first two years of a recovery period is to examine changes in the rates of growth of the money stock. ${ }^{4}$ For purposes of making comparisons with earlier periods, it is useful to relate the rate of monetary growth to its prevailing trend rate or, alter. natively, to deflate the money stock by the price level $(\mathrm{M} / \mathrm{P})$. The latter approach is employed here and the results are given in Table $I^{5}$

\footnotetext{
4All money stock computations in this section are based on data avalable pror to the February 1973 revision. For further information on this revision, see the statistical release entatled "Money Stock Neasures," Federal Reserve Board of Gov. emors (February 1, 1973).

ERelating money (M) to prices (P) in ratio form is not raeant to imply that the monetary authorities can directly confrol $M / P$. They can, however, control the smpply of $M$ within close tolerances. When the supply of $M$ exceeds the public's
} 


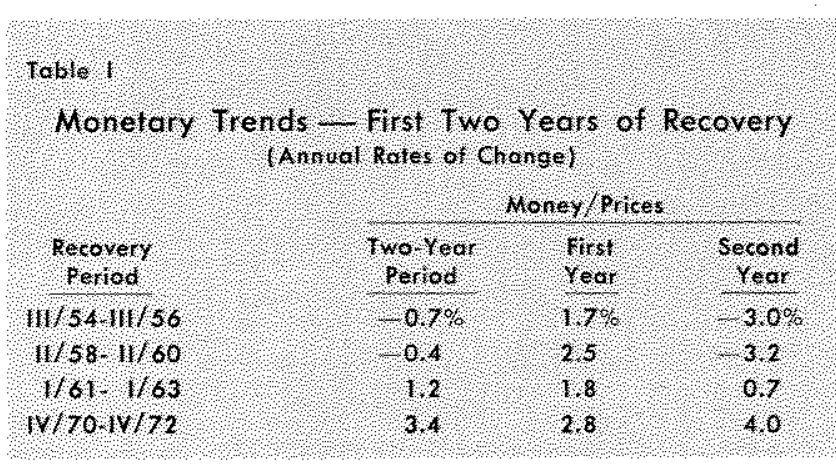

The data in Table I indicate that the money stock relative to prices actually fell slightly in the first two years of the recoveries which began in 1954 and 1958 . The finding of non-stimulative monetary actions for these particular periods is not surprising in view of the brevity of the recoveries which began in 1954 and 1958. In order to combat inflationary pressures, stimulative actions were reversed at an early stage in those two recoveries, as suggested by the switch from a positive rate of change in the $\mathrm{M} / \mathrm{P}$ atio in the first year to a negative figure in the second year.

The money/prices ratio increased at a 1.2 percent rate in the first two years of the long recovery which began in 1961. Even more stimulative was the 3.4 percent rate of increase of the money/prices ratio from the fourth quarter of 1970 to the fourth quarter of 1972. The money stock had to increase at a considerably more rapid pace than it had in the earlier recoveries in order to attain the 3.4 percent figure, since prices were rising at a more rapid rate than in the earlier comparable two-year periods.

The ratio increased 2.8 percent in the first year of the latest recovery, but accelerated to a 4 percent increase in the year ending fourth quarter 1972 . Prices rose 3 percent from the fourth quarter of 1971 to the fourth quarter of 1972 , compared with a 3.6 percent increase in the preceding year. For the same periods the nominal money stock increased 7.2 percent and 6.6 percent, respectively. That is, acceleration of the $\mathrm{M} / \mathrm{P}$ ratio in the second year of the recent recovery was due to both a slowing in price rises and an increase in the growth rate of the money stock.

In addition to the increased monetary stimulus in 1972, income velocity - the rate at which the money

demand for real cash balances ( $M / P$ ), there is a tendency for spending, and eventually prices, to increase. For the twenty-five year period ending in $1971, \mathrm{M} / \mathrm{P}$ changed little, increasing at only a 0.2 percent annual rate. At times when the ratio rose much above this rate, inflation later began to accelerate until the stimulative monetary actions were reversed. During periods of restrictive monetary actions, the ratio tended to fall.

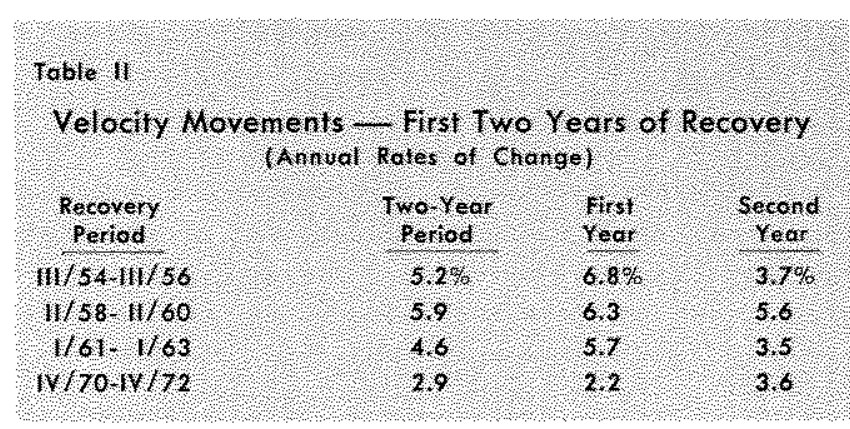

stock turns over - also accelerated. ${ }^{\text {F }}$ For the twoyear recovery period, velocity increased in the latest recovery at little more than half the average for the three preceding two-year periods (Table II). However, in each of the three earlier recoveries velocity increased at a slower rate in the second year than in the first. In the 1970-72 recovery velocity rose at a more rapid rate in the second year.

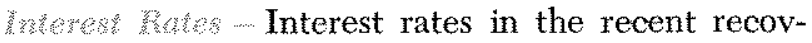
ery period have not displayed a pattern similar to earlier recovery periods. By the end of the second year, interest rates are normally above or near the levels prevaling at the start of the recovery. At the end of the second year of the recoveries begun in 1954 and 1958 , interest rates for three-month Treasury bills (a short-term rate) and corporate AAA bonds (a long-term rate) were well above their initial levels.

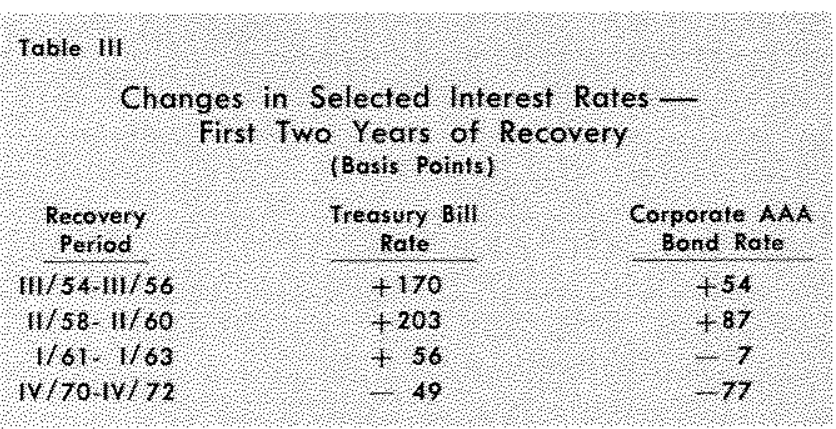

In the recovery begun in 1961 the Treasury bill rate rose 56 basis points in the first two years and the corporate bond rate remained relatively unchanged (down 7 basis points). By contrast, the Treasury bill yield in the fourth quarter of 1972 was almost 50 basis points lower than in the fourth quarter of 1970 ; the corporate AAA rate was down 77 basis points from the level of fourth quarter 1970.

There are a number of factors which contributed to the unusual behavior of interest rates in the past

GSee Armen A. Alchian and Willam R. Allen, University Economics, 3rd ed. (Belmont, California: Wadsworth Pubu lishing Company, Inc., 1972), pp. $577-79$ for a discussion of the factors inflenenging "income velocity." 


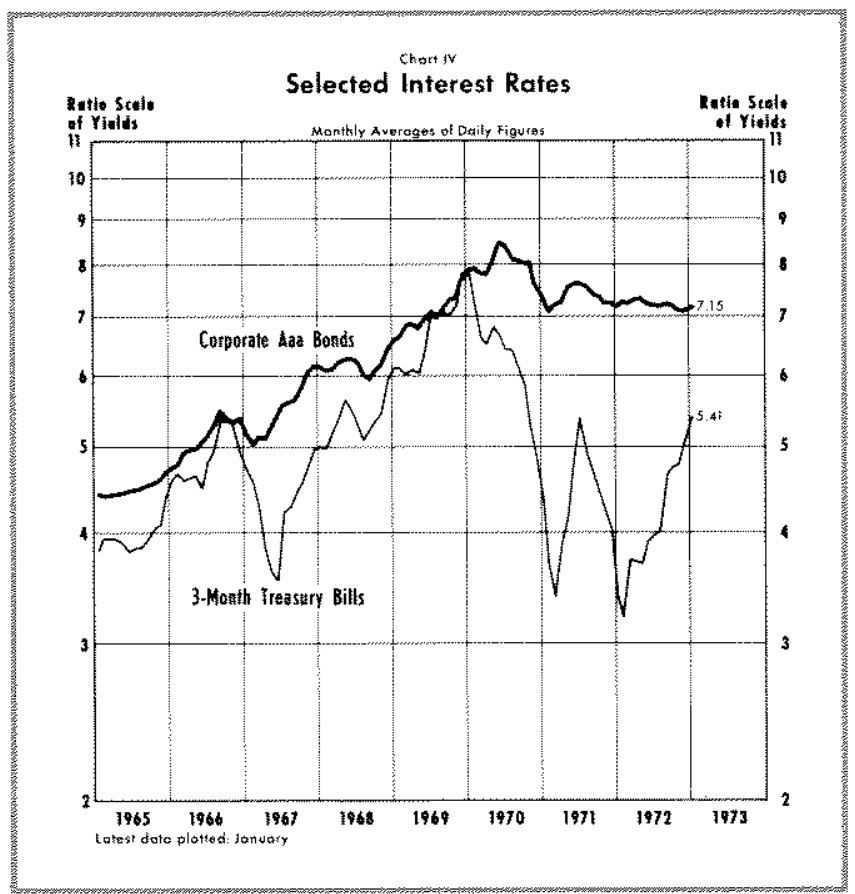

two years. The nominal money stock increased at greater rates recently than in earlier recovery periods. This more rapid growth of money probably contributed to short-run downward pressure on interest rates. The demand for funds, which picks up with business activity, is more difficult to quantify. However, after a rather sluggish first-year recovery in 1971, the strong business rebound in 1972 and early 1973 suggests intensifying upward pressures on interest rates.

Another possible factor influencing the behavior of interest rates during the past two years is the progress made in curbing inflation. Prices were rising much more rapidly at the start of the current recovery than in previous episodes, and thus there was considerably more room for them to decelerate than before. The drop in the rate of price increases from over 5 percent in late 1970 to about 3 percent at the end of 1972 could have been translated into a reduction in the inflationary premium built into market interest rates.

Finally, the controls program, in particular the awareness on the part of the business community of the potential exercise of direct interest rate controls, has probably had some restraining influence on certain yields. This influence was most apparent in such highly publicized interest rates as the "prime" rate charged by large commercial banks. The prime rate, like most other rates, has begun to increase in recent months.

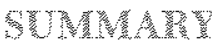

The economic recovery from the $1969-70$ recession moved off to a slow start in 1971, but accelerated rapidly last year. Business activity apparently has now advanced to the levels of the first two years of earlier recovery periods and appears to have sufficient momentum to continue into 1973 at a brisk pace. Some spending sectors, such as residential construction, are likely to taper off in 1973 , but others, most notably inventory accumulation, are expected to surge.

Total spending responds strongly to monetary and fiscal actions. The successively larger deficits of the Federal budget in the past few years will be followed by another deficit of considerable size in the current fiscal year. Money stock growth has increased at accelerating rates since 1969 , and far surpasses the growth rates of the first two years of previous recovery periods.

Interest rates thus far have remained below their levels of two years ago, in contrast to earlier comparable periods. However, the rapid pace of business activity, a sizable Federal budget deficit, and possible anticipation of a pickup in the inflation rate may prompt a return of interest rates to their normal cyclical pattern.

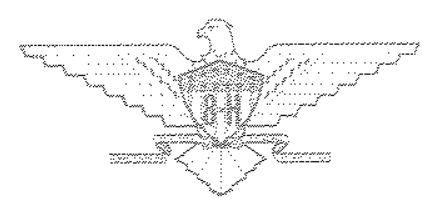

